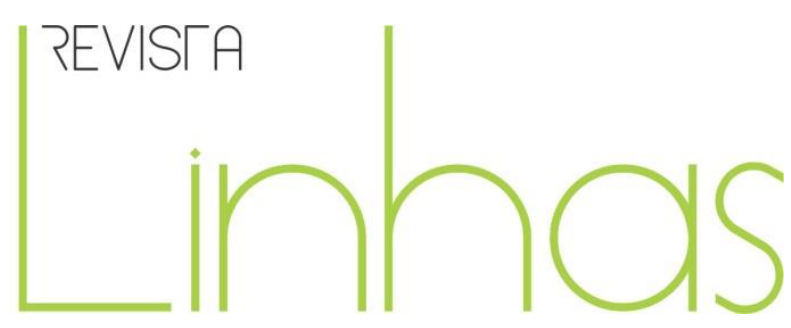

\title{
Constituição de um acervo documental sobre a história da Educação Infantil em Santa Catarina na primeira metade do século $X X$
}

\begin{abstract}
Resumo
O objetivo deste texto é mostrar o percurso trilhado para acessar os acervos e indicar arquivos e fontes sobre as primeiras iniciativas de atendimento educacional à primeira infância no estado de Santa Catarina. Estudos e pesquisas que se ocupem da localização de acervos, da discussão sobre levantamentos realizados, da sua disponibilização, poderão sugerir novas interrogações, novos objetos para o fortalecimento da prática da pesquisa histórica neste âmbito educacional e, consequentemente, para a produção de novos conhecimentos sobre o tema. Trata-se de uma pesquisa histórica sobre Educação Infantil em Santa Catarina, na primeira metade do século XX, cujos resultados apontam para a existência de arquivos e acervos pouco explorados, de caminhos para acessá-los e de reflexões acerca da necessidade dessas buscas e da conservação desses acervos, para que a história da Educação Infantil catarinense possa ser escrita e/ou reescrita.
\end{abstract}

Palavras-chave: Educação de Crianças. Santa Catarina. História.

\author{
Rosa Batista \\ Universidade do Sul de Santa \\ Catarina - Unisul - Tubarão/SC - \\ Brasil \\ rosab@terra.com.br \\ Leonete Luzia Schmidt \\ Universidade do Sul de Santa \\ Catarina - Unisul - Tubarão/SC - \\ Brasil \\ leonetes@gmail.com
}

\footnotetext{
Para citar este artigo:

BATISTA, Rosa; SCHMIDT, Leonete Luzia. Constituição de um acervo documental sobre a história da Educação Infantil em Santa Catarina na primeira metade do século XX. Revista Linhas. Florianópolis, v. 19, n. 41, p. 292-324, set./dez. 2018.
} 


\title{
Constitution of a documental collection about childhood education history in Santa Catarina in the Century 2oth first half
}

\begin{abstract}
The aim of this text is show the path walked to access the collections and indicate archives and sources on the early initiatives for educational attendance to the early childhood in the state of Santa Catarina. Studies and researches that aim to find the collections, the discussions on the survey performed and their availability could suggest new questions, new objects to strengthen the practice on history research in this educational scope, and consequently to produce new knowledge on the theme. It is a history research on Childhood Education in Santa Catarina in the 2oth Century first half, whose results point to the existence of archives and collections few explored, paths to access them and reflections on the need for these searches and conservation of collections, to the Childhood Education history in Santa Catarina could be written and/or re-written.
\end{abstract}

Keywords: Education of Children. Santa Catarina. History. 


\section{1 - Introdução}

O levantamento e a organização de fontes documentais referentes à história da Educação Infantil em Santa Catarina tiveram início durante o curso de Doutorado em Educação (2008-2013), com a pesquisa intitulada “A emergência da docência na Educação Infantil no Estado de Santa Catarina: 1908-1940"1. O objetivo foi analisar as origens históricas da docência e as determinações sociais, econômicas e políticas que influenciaram a instalação de Jardins de Infância e Creches no estado. Este estudo evidenciou a necessidade de identificar fontes e sistematizar estudos para contribuir com a produção do conhecimento sobre a história da Educação Infantil de Santa Catarina, e também do Brasil.

Importante considerar que a produção científica sobre Educação Infantil tem exigido uma interlocução com campos teóricos, entre eles a História, que permitam compreender os diferentes aspectos que estão envolvidos nas relações educativas. Como afirma Freitas (1999, p. 12), “o rastreamento da história da infância nas fontes primárias e secundárias têm carecido a travessia de um labirinto no qual as disciplinas e os territórios epistemológicos estão demarcados”. Destaca-se, desse modo, a importância do diálogo interdisciplinar presente no discurso da Educação e na utilização das fontes históricas, compreendendo que a história, “embora tratando do passado, do que já aconteceu, é dinâmica e exige a ampla pesquisa e a crítica das fontes, que renova interpretações e exige procedimentos próprios de investigação e análise” (KUHLMANN Júnior, 1998, p. 7).

Santa Catarina pouco sabe sobre as origens da Creche e do Jardim de Infância e as condições sociais (políticas, econômicas, religiosas, jurídicas e pedagógicas) nas quais emergiram. Isso fica evidente quando comparado a estados como Rio de Janeiro, São Paulo, Minas Gerais, Paraná e outros de grande porte, que dispõem de produções significativas no campo da historiografia da Educação Infantil.

As primeiras buscas de informações históricas também evidenciaram que não só havia pouca coisa escrita como também escassez de fontes em arquivos públicos no âmbito estadual e municipal. Isso levou ao entendimento, naquele momento, de que o acesso a possíveis acervos existentes sobre as primeiras iniciativas de Creche e Jardim de

\footnotetext{
${ }^{1}$ Ver BATISTA, Rosa. A emergência da docência na Educação Infantil no Estado de Santa Catarina: 1908-1949. Florianópolis: UFSC, 2013.
} 
Infância exigiria um trabalho de garimpagem a partir das evidências identificadas nos documentos (relatórios, decretos, jornais, entre outros) que versavam sobre as políticas de assistência e educação à pequena infância no estado. Seguindo a direção de Thompson (1981, p. 38), “A evidência histórica existe, em sua forma primária, não para revelar seu próprio significado, mas para ser interrogada por mentes treinadas numa disciplina de desconfiança atenta". Outras evidências foram identificadas na historiografia da Educação Infantil referentes ao surgimento dessas instituições e sua vinculação, de modo acentuado, à história da assistência às crianças em asilos, reformatórios, orfanatos, abrigos e internatos, denominadas de formas diversas, conforme o momento histórico e a classe social a que se direcionavam.

Em 2014, ao iniciar o estágio pós-doutoral, vinculado ao Programa Nacional de PósDoutorado (PNPD) $)^{2}$, um dos objetivos da pesquisa foi identificar arquivos e fontes relacionados à história da Educação Infantil em Santa Catarina. Nesse período, ao revisitar o acervo já organizado, foi tomando corpo a ideia de tornar pública a trajetória percorrida para o levantamento e organização dos documentos e respectivos locais e fontes em que se encontram elementos dessa história, por se entender que isso poderá contribuir com outros pesquisadores, tanto locais como nacionais, para que novas interrogações sejam feitas e o conhecimento acerca da história da Educação Infantil seja ampliado. De acordo com Thompson (1981, p. 49), “O conhecimento histórico é, pela sua natureza, a) provisório e incompleto [...] b) seletivo [...] c) limitado e definido pelas perguntas feitas à evidência [...] e, portanto, só 'verdadeiro' dentro do campo assim definido”. Ou seja, diferentes interrogações podem ser feitas às mesmas fontes ampliando, com isso, o conhecimento já produzido sobre a Educação Infantil.

Considerando esse entendimento e a lacuna na produção historiográfica brasileira sobre a Educação Infantil de Santa Catarina, pretende-se contribuir para a escrita dessa história, dando visibilidade a arquivos e fontes localizados durante o processo de pesquisa. Destaca-se que o significado de fonte aqui atribuído tem como base as definições de Saviani (2006, p. 30):

\footnotetext{
2 Pós-doutorado, PNPD/CAPES em andamento no Programa de Pós-Graduação em Educação da Universidade do Sul de Santa Catarina (UNISUL).
} 
As fontes estão na origem, constituem o ponto de partida, a base, 0 ponto de apoio da construção historiográfica que é a reconstrução, no plano do conhecimento, do objeto histórico estudado. [...] Elas, enquanto registros, enquanto testemunhos dos atos históricos, são a fonte do nosso conhecimento histórico, isto é, é delas que brota, é nelas que se apoia o conhecimento que produzimos a respeito da história.

Também se reitera a posição do autor sobre a importância em se desenvolver uma "preocupação intencional e coletiva com a geração, manutenção, organização, disponibilização e preservação das múltiplas formas de fontes da história da educação brasileira" (SAVIANI, 2006, p. 33).

Considera-se essa preocupação pertinente. Caso contrário, a construção historiográfica acerca da trajetória da Educação Infantil pode ser comprometida tanto pelo desconhecimento dos acervos que já existem nos arquivos, bibliotecas e mesmo museus, quanto pela ausência de recolha, organização e preservação das fontes documentais distribuídas em arquivos públicos estadual, municipais e particulares, além dos documentos privados e de associações. De acordo com Demerval Saviani,

O trabalho de organização dos acervos é decisivo e de grande importância para o desenvolvimento da pesquisa. Na medida em que pudermos contar com um número crescente de instituições de memória com acervos documentais adequadamente organizados e dotados de instrumentos que facilitem e agilizem o acesso às fontes, o trabalho dos pesquisadores será grandemente facilitado, com impacto significativo na qualidade das pesquisas e também em sua quantidade, uma vez que, nessas condições, o tempo de busca e de manipulação das fontes será fortemente reduzido. (SAVIANI, 2005, p. 7)

Assim, para dar visibilidade a arquivos e fontes referentes à história da Educação Infantil em Santa Catarina localizados durante as pesquisas, o texto foi organizado a partir de dois aspectos: a) o percurso trilhado para acessar os acervos; b) a indicação de arquivos e fontes localizados acerca das primeiras iniciativas de Creche e Jardim de Infância no estado. 
A opção de tornar público o percurso trilhado para o levantamento de arquivos e fontes referentes à história da Educação Infantil em Santa Catarina está relacionada ao entendimento de que esta trajetória pode contribuir com outros historiadores na indicação de lugares em que podem ser localizados dados referentes à temática, assim como oferecer pistas que os levem a outros acervos, ainda não identificados. A busca de fontes sobre as primeiras iniciativas de Creche e Jardim de Infância para analisar as emergências da docência na Educação Infantil passou pela contextualização dos marcos históricos definidos por alguns autores. Entre as principais obras, podemos citar Kramer (1982); Kishimoto (1986); Vieira (1986); Civiletti (1988); Bastos (2001); Kuhlmann Júnior (1998) e Souza (2004).

Foi realizada uma imersão nas pesquisas sobre a história da Educação Infantil no Brasil, cujas produções indicassem, além do percurso feito, fontes primárias e secundárias que pudessem vir a contribuir para a identificação da presença-ausência de elementos relativos à constituição histórica da Educação Infantil no país. Dentre as questões que guiaram essa imersão, destacamos duas que consideramos fundamentais: a) as determinações políticas, sociais, culturais e econômicas e a circulação de ideias que incidem sobre a criação do Jardim de Infância e Creche nos estados do Rio de Janeiro, São Paulo, Minas Gerais, entre outros, foram também definidoras da constituição do Jardim de Infância e da Creche no estado de Santa Catarina?; b) as fontes que constituíram o corpus documental das pesquisas trazem indicativos das tendências pedagógicas, políticas, projetos e propostas nacionais e regionais para educação da pequena infância daquele período?; no que se aproximam, se distanciam e/ou se complementam?

Tais questões perpassam a história da Educação Infantil de Santa Catarina (embora pouco conhecida), que expressa singularidades que constituem os diferentes processos de apropriação das ideias e dos agentes que protagonizaram a criação do Jardim de Infância e da Creche, assim como as particularidades sociais, culturais, políticas e econômicas que caracterizaram as diferentes regiões do estado. Dentre elas, destaca-se o forte contingente de imigrantes alemães e italianos e as realizações no campo da educação promovidas pelas congregações religiosas protestantes e católicas. É nesse sentido que se buscou, na historiografia da Educação Infantil indícios, pistas que viessem 
a contribuir para o desenvolvimento da pesquisa, pois, de acordo com Kuhlmann Júnior (1998, p. 8), "são pesquisas que desbravaram terrenos inexplorados no campo da história da educação, vulneráveis, portanto, aos tropeços e às críticas, mas abrindo espaço para estudos posteriores".

Sonia Kramer, em 1980, inaugura a pesquisa histórica no âmbito da Educação Infantil com sua dissertação de mestrado intitulada "História e política da educação préescolar”, publicada em 1982 com o título “A Política da pré-escola no Brasil: a arte do disfarce", pela editora Achiame. O título indica que se trata de um estudo crítico sobre a educação pré-escolar no Brasil. Para a autora, a história do atendimento à criança brasileira está dividida em dois momentos distintos: anterior a 1930, marcado pela proteção à saúde, e de 1930 a 1980, pela assistência social e educação numa perspectiva compensatória. A autora aponta a multiplicidade de órgãos criados pelo estado e suas intervenções na educação da criança.

Civiletti (1988), em sua pesquisa "A creche e o nascimento da nova maternidade", analisa os discursos e as práticas relativas ao atendimento de crianças pequenas no Brasil do século XIX. Faz referência ao surgimento da Creche no Brasil tomando como uma das referências o periódico “A mãi de família” que, a partir de 1879, assume a defesa da Creche como espaço beneficente para as mães trabalhadoras (escravas ou ex-escravas).

As principais pistas indicadas por esses estudos iniciam com a identificação das influências dos precursores europeus na criação e organização do Jardim de Infância (KISHIMOTO, 1986) e passam pela identificação das marcas de uma educação pré-escolar associada à educação compensatória. Vieira (1986) diz que a Creche no Brasil afirma-se como "mal necessário", como um lugar de compensar carências. Além disso, seu estudo traz importantes contribuições acerca das políticas públicas não obrigatórias para as crianças de 0 a 6 anos desenvolvidas pelos governos republicanos de Minas Gerais durante o século XX, e permite identificar o primeiro Jardim de Infância público de Minas Gerais, em 1908. Kuhlmann Júnior, no seu livro "Infância e Educação Infantil: uma abordagem histórica" (1998), amplia consideravelmente o conhecimento a respeito da constituição histórica das instituições pré-escolares assistencialistas no Brasil, no período de transição do século XIX ao XX. Outros trabalhos desse autor estão relacionados ao 
Jardim de Infância e à educação das crianças pobres (2001), bem como à circulação das ideias referentes à educação das crianças brasileiras no início do século XX (2002).

Foram ainda localizados os estudos de Bastos (2001) acerca do Jardim de Crianças e o pioneirismo do Dr. Menezes Vieira (1875-1887). Esta pesquisa equipara a professora do Jardim de Infância a uma "mãe zelosa do futuro de seu filho", numa época em que se redimensionava o papel da mulher, que não se restringia mais somente à esfera familiar (privada), estendendo-se para a esfera escolar (pública).

O estudo de Souza (2004) trouxe importante contribuição para esse processo. Ao examinar a constituição de uma forma escolar infantil e primária, por meio do estudo da cultura escolar dos Jardins de Infância e Grupos Escolares no Paraná entre 1900 e 1929, evidencia que os jardins de infância, junto aos grupos escolares, compõem o projeto civilizador de instrução republicana paranaense do limiar do século XX. Essa indicação de Souza sugere novos locais em que podem existir fontes sobre a educação infantil. São pistas como essas que mostram caminhos para a escrita da história da Educação Infantil do Estado.

Outra contribuição nesse sentido veio do levantamento de fontes elaborado por Rocha (2012), que analisa os artigos da revista "A mãi de família" 3 , relativos à Creche. Os artigos revelam uma defesa da Creche e definem suas origens e funções. Dentre elas, a de que a Creche é considerada um meio de diminuir a miséria e aumentar a população (Rio de Janeiro, 1879). Outros artigos sobre Creche e o papel da mãe são publicados na mesma revista, com ênfase na importância do amor materno, apresentando índices sobre a mortalidade infantil na Europa e no Brasil e destacando a proteção da infância e a educação da família como bases para o progresso e a felicidade da pátria. Chama atenção para a defesa da união das senhoras para a fundação de uma Associação Protetora das Crianças - créches ou asylos, de forma a proteger as crianças abandonadas nas ruas, principalmente após a Lei do Ventre Livre (ROCHA, 2012, p. 8-12).

De posse do percurso histórico, do conjunto de fontes e lugares evidenciados nos estudos citados anteriormente, uma busca presencial foi realizada junto aos arquivos da Biblioteca Nacional (RJ). O levantamento permitiu identificar e organizar fontes que vêm

\footnotetext{
${ }^{3}$ Ver dados quadro 1.
} 
subsidiando a constituição de um histórico da Educação Infantil, localizadas em documentações de referência publicadas em periódicos nacionais entre o século XIX e XX, e depositadas na Biblioteca Nacional.

Quadro 1 - Fontes localizadas na Biblioteca Nacional do Rio de Janeiro A Mãi de Família - Jornal Scientífico Literário e Ilustrado. Rio de Janeiro, Typographia dos Editores, Lombaerts \& Comp., jan./mar. - set./dez. 1879; jan. 1880; abr. 1883; jan. 1884; dez 1886; Abr/out 1887; Jan/dez 1888.

Revista do Jardim de Infância. V. I e II. São Paulo, Typographia de Espindola, Siqueira e Comp., Publicação Official do Governo do Estado de São Paulo, 1896 1897 (impresso).

Archivos de Assistencia a Infancia. Nov. 1902; set. 1907; jan. 1913; dez. 1925; jan. 1929; dez. 1946. Rio de Janeiro.

Archivos de Assistência à infância: órgão oficial do Instituto de Proteção à Assistência à Infância do Rio de Janeiro.

IMBERT, J. B. A. Guia medica das mães de familia, ou A Infancia considerada na sua hygiene, suas molestias e tratamentos. Rio de Janeiro: Typographia Franceza, 1843.

Quadro organizado pelas autoras.

Nessa primeira etapa do levantamento, foi identificada a documentação que tratava da temática da infância, da criança e sua educação, a partir de microfilmes e originais. As principais referências encontradas, conforme aparece no Quadro 1, referemse a jornais, revistas e relatórios, entre outros. Ainda nas leituras sobre a historiografia da Educação Infantil brasileira, também as produções de Moncorvo Filho foram inúmeras vezes citadas pelos/as autores/as, fato esse que demandou acessar os arquivos de tais produções, disponíveis on-line na Biblioteca da Pontifícia Universidade Católica do Rio de Janeiro (PUC-RJ). Nos arquivos on-line dessa biblioteca, encontramos os seguintes documentos relacionados às produções de Moncorvo Filho.

Quadro 2 - Produções do Instituto Moncorvo Filho (arquivos on-line Biblioteca PUC/RJ) A infancia da primeira edade no Rio de Janeiro [recurso eletrônico]: (trabalho do Dispensário Moncorvo Filho) / Congresso Latino Americano, 4, 1909, Rio de Janeiro; nota apresentada [por] Moncorvo Filho.

Estatutos do Departamento da Creança no Brasil [recurso eletrônico]: fundado pelo Dr. Moncorvo Filho em $1^{\circ}$ de março de 1919.

Dr. Moncorvo Filho. Breves considerações sobre um programa de Protecção á 
Infancia (apresentado á Conferência Feminista de 1922 no Rio de Janeiro). Trabalho do Departamento da Creança no Brasil. Rio de Janeiro: Typ. Besnard Frères, 1923.

Dr. Moncorvo Filho. Instituto de Protecção e Assistência á Infancia do Rio de Janeiro. Archivos de Assistência á Infancia. Distribuição Gratuita. Rio de Janeiro, 1917.

Moncorvo Filho, Arthur. Archivos de assistência á infância. Rio de Janeiro. V. III, N. 1-3, jan. fev. mar., 1904.

Dr. Moncorvo Filho. Algumas considerações sobre o problema da infancia no Brasil. Departamento da Creança no Brasil. Ublicação n 79, s.d.

Dr. Almeida Pires. Das amas de leite. Trabalho do Dispensário Moncorvo. Quarto congresso Latino Americano. Rio de Janeiro: Imprensa Nacional, 1909.

Quadro organizado pelas autoras.

No acervo da Fundação Carlos Chagas foram identificados documentos referentes ao Departamento Nacional da Criança (DNCr). Grande parte das produções acadêmicas relacionadas à história da educação que versam sobre as primeiras instituições de educação para as crianças pequenas no Brasil aponta para a necessidade da imersão nas produções deste departamento. Criado em 1940 com objetivo de amparar a maternidade, tinha como premissa a relação entre educação e saúde, no sentido de que à primeira cabia a formação moral e de hábitos higiênicos, como também a inculcação dos ideais do Estado Novo. Já à segunda cabia a responsabilidade de sanear o espaço social através de uma política de higienização da população pobre. O acesso aos dados deste departamento deu-se por meio de página na internet da Fundação Carlos Chagas (FCC), que possibilitou o contato com livros publicados entre os anos de 1940 e 1960.

Quadro 3 - Acervo Departamento Nacional da Criança

ANDRADE FILHO, Odilon de; BARROS FILHO, Sebastião; HIRTH, Maria Bernadette Pereira. Creches (Organização e Funcionamento). Rio de Janeiro: Ministério da Saúde/Departamento Nacional da Criança, 1956. (Coleção DNCr No. 151).

BARRETO FILHO, Oscar. Aspectos legais do problema das "creches”. Serviço Social, São Paulo, julho-setembro/1950.

BRASIL. Ministério da Saúde. Departamento Nacional da Criança. Clube de mães da Campanha Educativa. (Coleção DNCr. Rio de Janeiro, 1960).

DÓRIA, Ulysses. O problema dos menores (estudos e anotações). São Paulo: Imprensa Oficial do Estado, 1951.

FIGUEIREDO, Gastão de. Creche. 2. ed. Rio de Janeiro: Ministério da Educação e Saúde/Departamento Nacional da Criança - Imprensa Nacional, 1946. (Coleção D.N.Cr. $\left.\mathrm{n}^{\circ} .95\right)$.

FIGUEIREDO, Gastão de. Como prospera o bebê (F. Briguiet). Rio de Janeiro, 1938. 
FIGUEIREDO, Gastão de. Creche. Imprensa Oficial. Rio de Janeiro, 1946.

MANCINI, Guiomar Urbina Telles. As creches como auxiliares da Família. Serviço Social, São Paulo, set. 1944.

MINISTÉRIO DA EDUCAÇÃO E SAÚDE. Departamento Nacional da Criança. Inquéritos sôbre as instituições de proteção à maternidade e à infância. Rio de Janeiro: Departamento de Imprensa Nacional, 1952. (Coleção D.N.Cr.).

OLIVEIRA, Olinto de. A casa da criança. 3. ed. Rio de Janeiro: Ministério da Educação e Saúde/Departamento Nacional da Criança - Imprensa Nacional, 1946. (Coleção D.N.Cr. No. 72).

VASCONCELOS, J. Freire de; SILVEIRA, Sampaio. Problemas médico-sociais da infância, o comércio das criadeiras. Livraria Odeon. Rio de Janeiro, 1938.

Quadro organizado pelas autoras.

Disponível em: <http://www.fcc.org.br/pesquisa/jsp/educacaolnfancia/index.jsp>.

Neste levantamento de fontes que anunciam elementos constituidores da história da Educação Infantil, ainda encontramos disponibilizado no site da Fundação Carlos Chagas (FCC) um conjunto de documentos da Associação Feminina Beneficente e Instructiva (AFBI), criada por Anália Franco, entre eles, o jornal A vóz maternal. "Este jornal era o órgão de comunicação da AFBI e começou a ser publicado em dezembro de 1903. Há referências sobre a existência do jornal ainda na década de 1910" (FCC, 2011). Outras publicações desta mesma Associação são seus relatórios, manuais e livros de leitura para escola maternal.

Quadro 4 - Associação Feminina Beneficente e Instrutiva - AFBI

A Vóz Maternal. Anno I, $\mathrm{n}^{\circ} 2$ a $\mathrm{n}^{\circ}$ 12. São Paulo, $1^{\circ}$ de Janeiro de 1904 a $1^{\circ}$ de Novembro de 1904.

A Vóz Maternal. Anno II, n 1 . São Paulo, $1^{\circ}$ de Dezembro de 1904. ANCO, Anália; CALDAS, Eunice. Manual para Escolas maternaes. São Paulo: TipoLithographia Ribeiro, 1902, primeiro trimestre.

FRANCO, Anália. Lições aos pequeninos. São Paulo: Typ. A Vóz Maternal, 1914.

FRANCO, Anália. Leituras progressivas para creanças. São Paulo: Typ. A Vóz Maternal, livros 1 e 2, 1906; 1909.

Associação Feminina Beneficente e Instrutiva. Terceiras Lições para as Escholas Maternaes. Colleccionadas por Anália Franco. São Paulo: Typ. A Vóz Maternal, 1905. Associação Feminina Beneficente e Instrutiva. Novo manual educativo para nossos filhos. $7^{\circ}$ e $8^{\circ}$ fascículos. São Paulo: Typ. A Vóz Maternal, 1906.

Associação Feminina Beneficente e Instrutiva. Relatório de 1909. São Paulo: Typ. A Vóz Maternal, 1909.

Associação Feminina Beneficente e Instrutiva. Relatório de 1912. São Paulo: Typ. O Globo, 1913. 
Quadro organizado pelas autoras.

Disponível em: <http://www.fcc.org.br/pesquisa/jsp/educacaolnfancia/index.jsp>.

Essa imersão nas pesquisas, como nas fontes documentais relativas aos projetos, propostas e políticas em torno da educação da pequena infância, foi indicando que tanto as pesquisas e fontes de âmbito nacional quanto regionais ampliam a compreensão de que a constituição dessas instituições, bem como a emergência da docência nesses espaços, não pode ser tratada a partir de generalizações, mas de complementariedades. As regiões brasileiras, ou mesmo seus estados, foram sendo constituídos, povoados, colonizados, de modo diverso, influenciando sobremaneira a constituição das instituições educacionais para a pequena infância.

Nesse sentido, o mapeamento desse conjunto de documentos contribuiu significativamente para construir um roteiro de possíveis locais e fontes a serem encontradas em Santa Catarina, haja vista as dimensões relacionais entre o regional e o nacional. Alves (2001, p. 164) chama a atenção para a indissociabilidade dessas dimensões:

[...] os termos regional e nacional são expressões em escala diferente do singular. O universal corresponde ao movimento dado pela lei da totalidade, isto é, da sociedade capitalista, e o singular cinge-se ao lócus em que esse movimento se realiza: uma região, uma instituição educacional, a obra teórica e/ou prática de um educador, etc. Portanto, universal e singular são indissociáveis e os objetos de pesquisa só são suficientemente captados quando revelam essa indissociabilidade. Nesse sentido, as expressões nacional e regional não se opõem ao universal. São, isto sim, formas por meio das quais o universal se realiza. Como são formas sempre peculiares, em decorrência dos condicionamentos econômicos e culturais de cada região ou nação, são, por isso, expressões singulares de realização do universal. Sob esse aspecto, ao pesquisador das temáticas regionais cabe desvelar como a forma singular, que se expressa no seu objeto, realiza o movimento pertinente ao universal e como, para cada objeto investigado, se dá a mediação do nacional.

Assim sendo, o levantamento das fontes em níveis local/regional/nacional alarga as possibilidades de apreensão da História da Educação Infantil, na medida em que se pauta na categoria da totalidade social de cada momento histórico pois, independente do objeto de análise no campo das Ciências Humanas e Sociais que se almeje abordar no 
plano da historicidade, implica fundamentalmente tomá-lo na relação indissociável entre o estrutural e o conjuntural (FRIGOTTO, 2011). Contudo, "essa totalidade não é uma 'verdade' teórica acabada (ou Teoria); mas também não é um 'modelo' fictício, é um conhecimento em desenvolvimento, muito embora provisório e aproximado, com muitos silêncios e impurezas" (THOMPSON, 1981, p. 61).

A breve retomada da historiografia da Educação Infantil permitiu localizar o papel preponderante do movimento médico-higienista, no que se refere à educação e assistência às crianças nesse período, cujas preocupações dirigiam-se à saúde e à contenção dos males sociais originados da pobreza e que, certamente, ameaçavam os interesses da sociedade industrial emergente. Tal movimento deflagra a construção de discursos e práticas científicas, o surgimento de instituições e profissionais voltados para a criança e a infância, sendo a medicina, a lgreja, a indústria, as associações femininas de cunho filantrópico e caritativo aqueles que passam a ter como "objeto" privilegiado de intervenção a criança de 0 a 6 anos de idade. O surgimento dessas instituições sociais está vinculado à história da assistência às crianças e, na sua maioria, ligado às instituições religiosas de cunho caritativo e filantrópico (lembremos: denominadas de formas diversas, conforme o momento histórico e a classe social a que se direcionam).

Neste sentido, o campo de busca das fontes se expande para além dos arquivos do estado e municípios, para outras instituições que se interpõem, dentre elas, a família, a Igreja (católica e luterana) a fábrica, o Círculo Operário Católico e associações femininas de caráter religioso, caritativo e filantrópico que promoveram e demarcaram ações específicas orientadas em direção à assistência e à educação das crianças. Ou seja, implica considerar, em especial, os agentes que influenciaram e engendraram a sua criação.

\section{3- Arquivos e fontes em Santa Catarina}

A constituição de um acervo documental sobre a história da Educação Infantil exige diálogo com as fontes, com os sujeitos encontrados neste processo, e reiteração para o esclarecimento do que se busca, com a compreensão de que

O objeto imediato do conhecimento histórico compreende "fatos" ou evidências, certamente dotados de existência real, mas que só se tornam 
cognoscíveis segundo maneiras que são, e devem ser, a preocupação dos vigilantes métodos históricos. (THOMPSON, 1981, p. 49)

As fontes documentais garimpadas sobre a emergência das instituições de cuidado e educação das crianças pequenas em Santa Catarina, ao longo da primeira metade do século $\mathrm{XX}$, mostram indícios significativos referentes aos modos como as iniciativas de Jardim de Infância e Creches foram sendo gestadas em diferentes contextos sociais, geográficos, culturais e políticos.

Importante ressaltar que no período que compreende os anos de 1908 a 1949 ocorreram duas guerras, com consequências profundas para a sociedade catarinense. Entre elas, o projeto de nacionalização que "silenciou" uma parcela considerável de imigrantes europeus, como muitos projetos de educação em curso; período marcado também por profunda desigualdade econômica e social, gerada pelas contingências do processo de industrialização e urbanização que produz, ao mesmo tempo, uma elite detentora dos meios de produção e, também, um contingente de trabalhadores e trabalhadoras suscetíveis às condições de exploração e sujeitos à lógica patronal.

Em se tratando de um estudo de caráter histórico, é importante considerar que o atendimento às crianças em Creches e Jardins de Infância de Santa Catarina, na primeira metade do século XX, assim como em outros estados brasileiros, não se constituía como um direito e, portanto, não fazia parte de uma política de Estado, no sentido da garantia do acesso e condições concretas para efetivo atendimento, embora tenha sido anunciado no Decreto n. 348, de 7 de dezembro de 1907, que trata do Regulamento Geral da Instrução Pública:

\begin{abstract}
Nas escolas femininas da capital em que estiverem servindo pelo menos duas adjunetas, haverá ao cargo de uma delas, uma classe infantil na qual admittirão crianças, meninos e meninas de 4 até 6 anos. Essa classe será conduzida e dirigida segundo o regimen pedagógico dos - Jardins de Infancia -, para preparar as crianças pela educação dos sentidos, conforme os processos de Froebel. (SANTA CATARINA, 1908, p. 14)
\end{abstract}

Nas fontes localizadas (relatórios, decretos, mensagens), disponíveis nos arquivos privados e públicos do Estado, os dados obtidos referem-se inicialmente à classe infantil (1908) e, mais tarde (1938), aos cursos pré-primários vinculados à escola feminina da 
capital, aos Grupos Escolares e escolas primárias e ao Instituto Estadual de Educação. Ou seja, nesses documentos o uso da denominação pré-primário indica sua forte vinculação ao ensino primário, tornando aquele como uma questão secundária. Não foi encontrada, nos dados estatísticos oficiais sobre matrícula no período de 1908-1949, nenhuma referência a grupos de pré-primário de caráter público nos municípios, assim como sua organização pedagógica e profissionais que nele atuavam.

A ausência de uma política educacional voltada para as crianças menores de sete anos contribuiu para que outras entidades e instituições criassem, à margem do Estado, Creches e Jardins de Infância na esfera do privado. O que, de certo modo, pode ter contribuído para a escassez de fontes sobre as primeiras inciativas nos documentos oficiais do Estado. Destaca-se que, no Brasil, o processo de definição das responsabilidades sociais sobre as novas gerações desencadeou a construção de padrões de assistência e educação caracterizados por processos excludentes, não assegurando acesso igualitário à assistência, saúde e educação, produzindo a convivência de diferentes modalidades de serviços educativos em instituições diversas, e com diferentes profissionais. Só a partir de 1988 é que se define constitucionalmente o direito à Educação Infantil às crianças, antes do ingresso ao Ensino Fundamental.

Outro aspecto importante, quando nos referimos à escassez de fontes da história da Educação Infantil em Santa Catarina, diz respeito à política de nacionalização, que tem início na Primeira Guerra e é acentuada no período da Segunda Guerra, com o propósito de abrasileirar as regiões povoadas por imigrantes estrangeiros fixados nas diversas regiões do estado. Os Jardins de Infância criados pelas Associações Evangélicas nas regiões colonizadas por alemães, como Blumenau e Joinville, entre outros, foram alvos desse projeto. A vida de homens, mulheres e crianças de origem estrangeira, em especial os de origem alemã foi, por certo, silenciada e cerceada nas suas crenças, ideais e projetos de educação em curso. Seyferth (2003, p. 54) observa que:

A consequência imediata do "estado de guerra" com a Alemanha foi a proibição das publicações em língua alemã e o fechamento das escolas alemãs. [...] A partir de 1917, o empenho de grupos brasileiros para acabar com o "perigo alemão" se intensificou, criando-se inclusive algumas associações mais radicais, como a Liga de Resistencia Nacional [...] Tal associação pretendia despertar "o sentimento cívico dos brasileiros contra a Kultur germânica". 
Norberto Dallabrida, ao fazer a apresentação do livro de Cynthia Machado Campos (2008), cita os esforços estatais que foram envidados durante o Estado Novo, no sentido de normalizar a língua portuguesa no território nacional, obrigando o encerramento das atividades nas pré-escolas e escolas abertas pelas iniciativas privadas, em especial, a confessional luterana. Instituições estas que haviam se proliferado em décadas anteriores, muito por conta da omissão estatal.

Para localizar as fontes documentais que possibilitassem conhecer a história da Educação Infantil em Santa Catarina, além daquelas indicações presentes nas referências nacionais, recorreu-se, também, à leitura de estudos e pesquisas acadêmicas sobre a história das instituições educativas para crianças pequenas no estado, destacando-se estudos e pesquisas realizadas por: Biehl (2006), Rabelo (2007), Kilipper (2008), Serafim (2009), entre outras. Essas pesquisas apresentam as primeiras experiências de Jardins de Infância localizadas na região Sul do estado, no período de 1945 a 1960.

Além dessas referidas acima, também as pesquisas de Costa (1999), “Arte de Viver: Recriando e Reinventando Espaços - Memórias das Famílias da Vila Operária Mineira Próspera - Criciúma (1945/1961)”, e de Alves (2009), “Faces da assistência social do setor carbonífero (1930-1960)", trazem importantes contribuições acerca das determinações políticas, sociais, religiosas e econômicas que convergem com a criação do Jardim de Infância e, evidentemente, de fontes e arquivos pesquisados.

Na região do Alto Vale do Itajaí, Isotton (2004) desenvolveu uma pesquisa sobre as primeiras iniciativas de Jardim de Infância da cidade de Rio do Sul, nos anos de 1938 e 1948. Hoff, Longhi e Cardoso (2010) fazem referência à iniciativa do primeiro Jardim de Infância, em 1928, na cidade de Canoinhas, região que pertence ao Planalto Norte catarinense.

O contato com os resultados dessas pesquisas foi evidenciando a presença das congregações religiosas femininas e de associações das senhoras evangélicas na implantação e no desenvolvimento das ações educativas no Jardim de Infância, como também forneceu pistas sobre os possíveis paradeiros de fontes.

Após a leitura dos materiais citados anteriormente, iniciou-se visitas in loco em arquivos históricos de diferentes municípios catarinenses: Arquivo Histórico José Ferreira 
da Silva e Arquivo histórico da Cia. Hering, ambos de Blumenau; Arquivo Público do Estado de Santa Catarina (Florianópolis); Arquivo Público e Histórico de Tubarão; Arquivo Histórico de Criciúma; Arquivo Histórico de Joinville e Arquivo do Círculo Operário de Joinville; Biblioteca Pública do Estado de Santa Catarina.

Nessas andanças, foram encontrados relatórios da Legião Brasileira de Assistência (LBA), relatórios, decretos e mensagens do governo catarinense, documentos formados por atas, reminiscências, históricos, certidões civis, documentos privados em forma de crônicas e jornais veiculados nas primeiras décadas do século XX.

Essas fontes, já bastante numerosas, tal como bússolas, serviram para guiar por diferentes territórios geográficos catarinenses a busca de outros documentos que permitissem a composição de um corpus documental mais consistente.

O primeiro porto de paragem foi o Arquivo Público e Histórico de Tubarão, município distante aproximadamente 120 quilômetros de Florianópolis, lugar selecionado para um encontro com o diretor deste arquivo, Amadio Vittoretti. É ele quem apresenta padre Agenor Neves Marques, diretor da Casa da Criança de Criciúma e fundador do Paraíso da Criança, na cidade de Urussanga, e relata a chegada das Irmãs da Divina Providência a Tubarão, em 1895. Mais tarde, fundam o primeiro Jardim de Infância no estado.

Com essas informações, o passo seguinte foi a visita ao Colégio São José (criado pela Congregação da Divina Providência em 1895). Desta instituição, tem-se a informação da inexistência de documentos que fizessem menção a essa iniciativa. Entretanto, Pieri (2011) realiza uma pesquisa sobre a gênese do atendimento às crianças em instituições infantis no município de Tubarão (1950-1990) e apresenta dados que indicam a criação de um Jardim de Infância pelas Irmãs da Congregação da Divina Providência, no ano de 1908, iniciativa que não teve continuidade por falta de matrículas.

O próximo destino foi a cidade de Urussanga, município localizado a 50 quilômetros de Tubarão. Na Secretaria Municipal de Educação, foi concedida a cópia de uma certidão cujo teor consiste na organização e funcionamento do Paraíso da Criança, fundado em 15 de agosto de 1948. O contato com esse estatuto, aliado a informações orais sobre a existência do "Paraíso da Criança", levou a uma entrevista com Ida Bez 
Batti, secretária do "Paraíso da Criança" que participou da criação do Jardim de Infância, juntamente com o padre Agenor Neves Marques e Olinda Bettiol. Ida foi categórica ao dizer que possuía poucas lembranças do Jardim de Infância, mas enfatizou a importância dessa "grandiosa obra social".

De volta a Urussanga, com objetivo de conhecer outras pessoas que trabalharam com padre Agenor, obteve-se informação sobre Rosa Miotello, conhecedora e participante ativa das obras de caridade do "Paraíso da Criança" e de tantas outras ações realizadas pelo padre Agenor e por Ida Bez Batti. Pela confiança e amizade por Rosa Miotello, Ida decide disponibilizar seu "livro de crônicas do Paraíso da Criança 10/05/1948 a 30/10/1958", documento escrito por ela com ilustrações, fotografias e descrição detalhada do processo de sua criação e das atividades realizadas do Jardim de Infância. Neste município, foram localizadas as fontes constantes no Quadro 5, a seguir:

Quadro 5 - Arquivos e fontes sobre o "Paraiso da Criança"

\begin{tabular}{l} 
Arquivo pessoal de Ida Bez Batti - Urussanga \\
Livro de Crônicas do Paraíso da Criança (10/05/1948 - 30/10/1958). \\
\hline Secretaria Municipal de Educação de Urussanga - SC \\
Certidão emitida pelo Registro Civil de Urussanga, datada de 25 de janeiro de 1958, \\
tratando do estatuto do Paraíso da Criança. \\
MARQUES, Agenor Neves. História de Urussanga. Urussanga: Prefeitura Municipal, \\
1960.
\end{tabular}

Quadro organizado pelas autoras.

A sequência do roteiro foi na cidade de Criciúma, maior município do Sul do estado, mais especificamente no Colégio São Bento. Em entrevista com a diretora do Colégio, Irmã Analuísa Venturini, obtém-se informações e acesso a documentos que informam sobre o Jardim de Infância criado em 1945, pelo Círculo Operário São José, inicialmente dirigido pelo padre Agenor Neves Marques, com a participação das Irmãs Escolares de Nossa Senhora, que atuaram nos primeiros anos de trabalho. Posteriormente, o Jardim de Infância passou a compor uma das ações da Casa da Criança Nossa Senhora de Fátima, inaugurada em 19/03/1947 sob a direção das Irmãs Beneditinas da Divina Providência. Com essas informações, outros espaços foram visitados, dentre 
eles, o Arquivo Histórico Municipal Pedro Milanez de Criciúma, a Sede do Círculo Operário São José e a Curia Diocesana de Criciúma.

Quadro 6 - Arquivos e fontes sobre a Casa da Criança

\begin{tabular}{l} 
Arquivo Histórico de Criciúma (público) \\
Jornal Correio da Manhã de 28/12/1937. \\
\hline Arquivo Colégio São Bento - Criciúma (privado) \\
Histórico do Colégio São Bento. Texto Mímeo. Criciúma, s/d. \\
Livro de atas no 1 da Associação Católica Círculo São José, 1952. \\
Estatuto do Círculo São José de Cresciuma, (mímeo) 1935. \\
ARNS, Irmã Maria Helena. Histórico das Irmãs Escolares de Nossa Senhora. Colégio \\
Sagrada Família Forquilhinha - SC. Forquilhinha: Ellus Editora e Gráfica Ltda, 2000. \\
\hline
\end{tabular}

Quadro organizado pela autora.

No retorno a Florianópolis, iniciou-se uma busca junto à Biblioteca Pública Estadual que resultou na localização dos Relatórios da Legião Brasileira da Assistência (LBA, 1943, 1945, 1948), que apresentam dados sobre a existência do Centro de Puericultura Beatriz Ramos, localizado na Capital e que comportava, entre outras atividades, atendimento pré-escolar e Creche. Foram também identificados, nestes relatórios, registros de auxílio financeiro a duas instituições de atendimento às crianças em regime de Creche ou Jardim de Infância - Creche Conde Modesto Leal, de Joinville, e Casa da Criança, de Criciúma. Além desses, foram também localizados dois relatórios da Sociedade de Assistência aos Lázaros e Defesa Contra a Lepra em Santa Catarina (1941 e 1944), que informam sobre um Jardim de Infância dirigido por Irmãs Franciscanas no Educandário Santa Catarina, situado no município de São José, região da Grande Florianópolis.

Quadro 7 - Biblioteca Pública do Estado de Santa Catarina (BPESC Florianópolis)

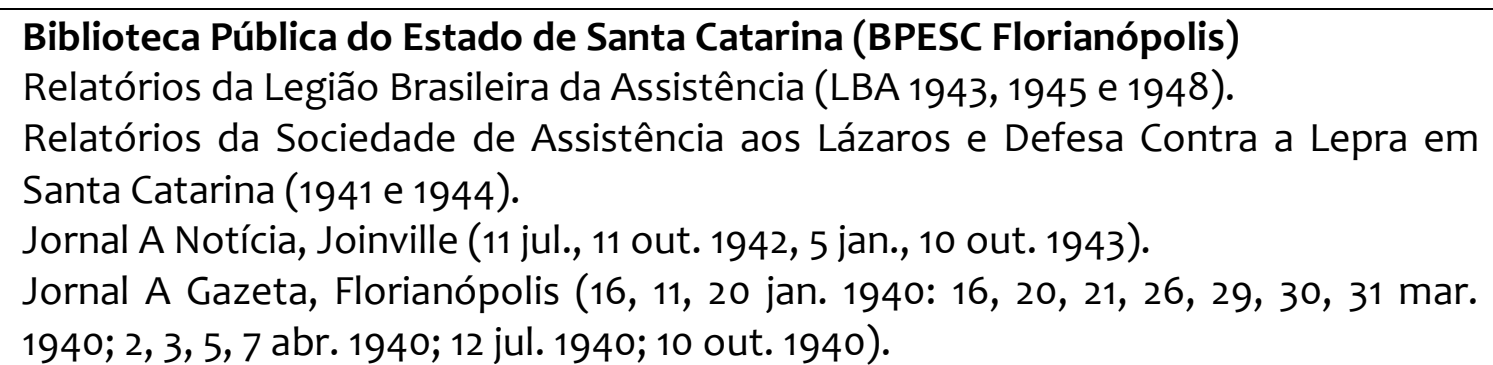

Quadro organizado pelas autoras. 
No Arquivo Público do Estado foi encontrado o relatório datado de 1938, apresentado pelo governador Nereu Ramos à presidência da República, que destaca dados estatísticos de matrícula e frequência entre os anos de 1935 e 1938, no Jardim de Infância do Colégio Coração de Jesus, mantido pelas Irmãs da Divina Providência no Centro de Florianópolis. Outro relatório com o mesmo objetivo foi apresentado em 1939 e faz menção aos Decretos $n^{\circ} 88$ e 142, que traçam orientações à nacionalização da educação pré-primária e primária. Também apresenta informações quanto à finalidade e organização dos institutos de educação, destacando que o curso pré-primário constituiria o Jardim de Infância (Decreto $\mathrm{n}^{\circ} 244$ ).

Quadro 7 - Arquivo Público do Estado de Santa Catarina (APESC Florianópolis) SANTA CATHARINA. Decreto n. 348, de 7 de dezembro de 1907. Regulamento Geral da Instrução Pública. Florianópolis, Typ. Gutenberg, 1908.

SANTA CATHARINA. Lei n. 967, de 22 de agosto de 1913.

SANTA CATARINA. Decreto-lei n. 306, de 2 de março de 1939 - reorganiza o Instituto de Educação. Coleção de Decretos-Leis de 1939, Florianópolis, 1939.

SANTA CATARINA. Relatório do Interventor Federal Nereu Ramos apresentado ao

Presidente da República. Florianópolis: Imprensa Oficial, 1939 e 1943.

Quadro organizado pelas autoras.

Como um dos referidos relatórios fez menção ao Colégio Coração de Jesus, contatou-se esta instituição objetivando acessar documentos que tratassem desse Jardim de Infância. Porém, foram disponibilizados apenas documentos que faziam referência à inauguração do Jardim de Infância, em 1956.

Nos relatórios da LBA, mencionava-se ajuda financeira à Creche Conde Modesto Leal, instalada na cidade de Joinville. Por isso, o passo seguinte foi o contato com esta instituição, o que resultou no recebimento do livro "Creche Conde Modesto de Leal: o legado social do Pe Alberto Kolb", de autoria de Carmen Silvia Meyer Miranda (2006). Este livro traz informações importantes, entre elas, o ano de criação da Creche (1936), o processo de sua fundação pelo Círculo Operário Católico de Joinville (COCJ) como também o paradeiro de documentos importantes para a pesquisa.

Nas dependências do COCJ foram encontrados livros de atas, histórico do COCJ, estatutos, livros de reminiscências, histórico do Círculo Operário através da imprensa, 
entre outros, sobre o processo de criação e desenvolvimento do trabalho educativoassistencial idealizado pelo padre Alberto Kolb e realizado pelas Irmãs da Ordem de São Vicente de Paula. Ainda na cidade de Joinville, foram localizadas pela internet informações referentes a outro Jardim de Infância da década de 1930, ligado à Igreja Evangélica Luterana. Na Paróquia da Paz da Comunidade Evangélica Luterana de Joinville, foi encontrado um histórico do Jardim de Infância da rua Jaguaruna, elaborado em 1963 por Dorothea Bühler, que assumiu o cargo de professora de 1925 a 1938. Neste documento, ela registra a data de fundação do Jardim de Infância - 17/05/1917, seu fechamento em seguida, em virtude da Primeira Guerra Mundial, sua reabertura, em 1920, e novamente o seu fechamento, no período da Segunda Guerra. Constam do documento os nomes das professoras que trabalharam nos períodos de 1917 a 1963.

Quadro 8 - Arquivos e Fontes sobre Creche Conde Modesto Leal e Jardim de Infância

\begin{tabular}{|l|}
\hline Arquivo Histórico de Joinville (público) \\
Álbum Histórico Centenário de Joinville: $1851-1951,1951$. \\
\hline Arquivo do Círculo Operário de Joinville (privado) \\
KOLB, Padre Alberto. Reminiscências para a história do Círculo Operário. Livros nº \\
$2 ; 4$. \\
KOLB, Alberto. Histórico do Círculo Operário através da imprensa. Fatos e não \\
palavras. Amparando os proletários catarinenses. Livros nº 1 [s/d]; 2 [s/d]; 3 \\
[1941/42]; 4 [1942/46]. \\
CíRCULO OPERÁRIO DE JOINVILLE. Atas - livro 1, 1935. \\
O Boletim do Círculo Operário de Joinville. Jornal mensal da entidade. \\
Súmula dos Estatutos dos Círculos Operários. Princípios Básicos. \\
\hline Arquivo da Paróquia da Paz - Joinville (privado) \\
Histórico sobre o Jardim de Infância da Rua Jaguaruna, 1963. \\
\hline
\end{tabular}

Quadro organizado pelas autoras.

$\mathrm{Na}$ trilha das comunidades evangélicas instaladas no estado catarinense, o próximo destino foi Blumenau, cidade onde foi fundado, pela Ordem Auxiliadora de Senhoras de Itoupava Seca - OASIS ${ }^{4}$ em 1935, um Jardim de Infância. Outras buscas foram realizadas por meio da internet com intuito de ampliar as informações acerca do histórico desta instituição, no site do Jardim de Infância Princesa Isabel e Jardim de Infância Tereza

\footnotetext{
${ }^{4}$ Ordem Auxiliadora de Senhoras de Itoupava Seca, da Paróquia Evangélica de Confissão Luterana de Itoupava Seca, de Blumenau.
} 
Cristina e no blog do historiador Adalberto Day. No arquivo histórico José Ferreira da Silva, além dos artigos referentes à Sociedade das Senhoras Evangélicas nos Cadernos de Blumenau, foi encontrado um documento com as atas das reuniões da Sociedade das Senhoras Evangélicas que trazia indicativos sobre as atividades realizadas e o desejo manifesto de criação do Jardim de Infância.

Quadro 9 - Arquivos e fontes sobre Jardim de Infância

\begin{tabular}{l} 
Blog de Adalberto Day - Blumenau - http://adalbertoday.blogspot.com.br/ \\
Assistência Social da Empresa Industrial Garcia - EIG. \\
Histórico da OASE - "Grupo Esperança” e Raízes da Paróquia Evangélica Luterana \\
"Bom Pastor" - Garcia. \\
\hline Arquivo Histórico José Ferreira da Silva - Blumenau (público) \\
Blumenau: Fundação Casa Dr. Blumenau. Centenário de Blumenau 1850 - 2 de \\
setembro - 1950. Blumenau: FCDB, 1950. \\
Relatório sobre a fundação e o trabalho da Sociedade Evangélica de Senhoras de \\
Blumenau (tradução dos originais manuscritos por Ellen Vollmer). s/d.
\end{tabular}

Quadro organizado pelas autoras.

Blumenau, uma cidade reconhecida pela sua tradição têxtil com duas empresas, Industrial Garcia S. A. e Cia. Hering, em plena ascensão na década de 1940, empregava um número expressivo de mulheres que, pelas leis trabalhistas (CLT), tinham como direito assistência e guarda de seus filhos até 1 ano de idade, durante o horário de trabalho. De posse dessas informações, as buscas foram feitas no arquivo do museu da Cia. Hering, que disponibilizou documentos referentes à criação da Creche (1935), organização, funcionamento e profissionais responsáveis pelo cuidado e assistência às crianças. No livro "Centenário de Blumenau 1850-1950", um artigo faz referência à Empresa Industrial Garcia S. A. como pioneira na implementação das leis sociais. Dentre os serviços assistenciais, propunha Creche para filhos das mulheres operárias. Porém, não foi localizado nenhum documento que tratasse da existência da mesma.

Quadro 10 - Arquivo e fontes sobre Creche da Cia. Hering

Arquivo histórico da Cia. Hering - Blumenau (privado) Indústria Têxtil Companhia Hering. Relatório da Diretoria e Parecer do Conselho Fiscal. Balanço Geral. Demonstração da Conta de Lucros e Perdas. Anexos e Outros Demonstrativos. Exercício Social 1944/45. 
Indústria Têxtil Companhia Hering. Fundação Hermann Hering. Regulamento. 1947. Santa Catarina: Secretaria do Interior e Justiça, Educação e Saúde. Departamento de Saúde Pública. Atestado. 1952.

Quadro organizado pelas autoras.

Essa trajetória foi marcada pelo garimpo das fontes, por vezes esquecidas em prateleiras e armários, ou cuidadosamente guardadas, organizadas em alguma estante de um arquivo, aguardando por serem tomadas nas mãos e analisadas. Pela busca por encontrar os sujeitos que se inscreveram por detrás dos discursos materializados no formato de crônicas, de matérias de jornais, de discursos manifestados em outros tempos. Nas fontes encontradas, indícios de uma história narrada pelos homens: padres, pastores, médicos, industriais, entre outros, o que revela que, embora estejamos diante de uma constituição profissional feminina, no âmbito das atividades educativas em Creche e Jardim de Infância, destaca-se a forte presença dos homens como protagonistas da história da Educação Infantil.

A partir das fontes até aqui encontradas, podemos afirmar que pouco sabemos sobre as profissionais que atuaram diretamente no trabalho educativo com as crianças pequenas. Segundo Perrot (1988, p. 186), “[...] o silêncio sobre a história das mulheres também advém do seu efetivo mutismo nas esferas políticas, por muito tempo privilegiadas como locais exclusivos de poder." À margem dos poderes e decisões políticas, as Mulheres-Irmãs, Mulheres-Diaconisas, Mulheres-leigas, Mulheresenfermeiras, Mulheres-Jardineiras protagonizam as práticas educativas no interior das instituições, lugar destinado a elas. Importante enfatizar que a religião se interpõe nas relações sociais que definem o lugar social dos homens e das mulheres:

A religião é reconhecidamente um espaço de ocultamento das mulheres. A ocupação dos espaços públicos e privados nas igrejas ainda é definida com base nas hierarquias de gênero, com as mulheres desempenhando, na maioria das vezes, a função de auxiliares dos homens, em papéis tidos como "naturalmente" femininos. (FARIAS, 2016, p. 17)

Nesta direção, Kuhlmann Júnior (1998, p. 92) também chama a atenção para o lugar social atribuído à mulher, muito mais na condição de coadjuvante dos processos sócio-educativos idealizados pelos homens, em especial os médicos e os puericultores: 
A participação da mulher na assistência era estabelecida numa linha de auxiliares da intervenção dos homens. As mães burguesas, as esposas e parentes dos promotores de associações assistenciais eram postas como aliadas dos médicos na tarefa de difusão dos novos comportamentos exigidos para a função materna, atuando como modelos junto às mães trabalhadoras.

Todavia, é preciso compreender homens e mulheres como sujeitos das experiências e, nesse sentido "As mulheres, não são passivas, nem submissas. [...] Elas traçam um caminho que é preciso reencontrar. Uma história outra. Uma outra história” (PERROT, 1988, p. 212).

A história sobre as experiências daquelas mulheres, sua formação e atuação direta com as crianças exige um trabalho de garimpagem de fontes que revelem outras evidências e que venham somar ao acervo em construção. Trata-se de reconstruir as experiências históricas daquelas mulheres que se lançaram no espaço da educação das novas gerações, cuja existência pode ter sido secundarizada em detrimento de um projeto de sociedade assentado na subalternidade das mulheres e crianças.

\section{4 - Considerações}

O propósito de contribuir com a construção de um acervo de fontes históricas sobre a emergência da Creche e Jardim de Infância do estado de Santa Catarina não se esgota neste trabalho. Este é o começo de um longo trabalho de pesquisa, que envolve o garimpo de outras fontes.

As inúmeras viagens realizadas durante a garimpagem das fontes permitiram, na maioria das vezes, um contato direto com as pessoas que fizeram parte desta história, com os locais onde começaram as experiências e com os documentos que registraram, de forma direta ou indireta, seu desenvolvimento, revelando os contextos e os percursos da história da Educação Infantil no estado. A cada lugar e pessoa visitada, novos documentos ou informações foram sendo agregados ao acervo que estava sendo construído. Esse trabalho exigiu percorrer as distâncias que iam sendo apontadas no mapa, na busca dos fios que teciam um conjunto de informações que corporificassem a 
compreensão das determinações políticas, sociais, econômicas, pedagógicas, que influenciaram as inciativas de Jardim de Infância e Creche no estado de Santa Catarina.

O intenso processo vivido de busca e localização das fontes alerta para o problema de preservação da memória e dos acervos históricos sobre Educação Infantil. Enquanto a memória da escola e do ensino primário pode contar com alguma organização no âmbito da esfera pública, a Educação Infantil carece de espaços ou registros oficiais com os quais se possa contar. Outro aspecto que merece ser observado refere-se à precariedade e instabilidade que caracterizaram o processo de constituição da Educação Infantil no estado e, portanto, conduzem a pensar que muitas fontes documentais podem ter se perdido, o que impede de assegurar a existência dessas experiências somente, pois algumas outras podem ainda estar na penumbra.

Nesse sentido, chamamos atenção para as dificuldades de encontrar fontes sobre a história da Educação Infantil em Santa Catarina, pelas muitas razões aqui apresentadas. Nossa realidade é a de carência das fontes preservadas, organizadas e sistematizadas, principalmente quando se trata das experiências realizadas nos Jardins de Infância no início do século XX, período que marca as primeiras inciativas. Todavia, a consciência de preservação da memória e de disponibilizar os acervos e arquivos para pesquisadores é uma realidade cada vez mais difundida e realizada no âmbito das leis nacionais de incentivo cultural, que promovem e incentivam a instauração de arquivos para sistematização e preservação da memória local.

Hoje, contamos também com inúmeros centros de documentação histórica, que colocam à disposição de todos os acervos importantes que contribuem para a escrita da história da Educação Infantil. Deste modo, talvez uma das contribuições deste trabalho seja a de dar início a esta sistematização da memória da Educação Infantil catarinense, de forma que, a partir dela, novas pesquisas possam se fazer e a lacuna da história da Educação Infantil de Santa Catarina na historiografia brasileira vá sendo preenchida. 


\section{Referências}

A MÃl de Família - Jornal Scientífico Literário e Ilustrado. Rio de Janeiro, Typographia dos Editores, Lombaerts \& Comp., jan./mar. - set./dez. 1879; jan. 1880; abr. 1883; jan. 1884; dez 1886; abr./out. 1887; jan./dez. 1888. Disponível em:

<http://bndigital.bn.br/acervo-digital/mai-familia/341703>. Acesso em 13/06/ 2013.

ALMEIDA PIRES. Das amas de leite. Trabalho do Dispensário Moncorvo. Quarto congresso Latino Americano. Rio de Janeiro: Imprensa Nacional, 1909. Disponível em: $<$ http://www2.dbd.puc-

rio.br/pergamum/docdigital/MoncorvoFilho/Rolo3/6_Das_amas_de_leite.pdf $>$. Acesso em: 08/03/2013.

ALVES, Gilberto Luiz. Nacional e regional na história educacional brasileira: uma análise sob a ótica dos estados mato-grossenses. In: SBHE: Educação no Brasil. São Paulo: Autores Associados: SBHE, 2001, p. 163-188.

ALVES, Ismael Gonçalves. Faces da assistência social do setor carbonífero (Criciúma, 1930-1960). 2009. 150 f. Dissertação (Mestrado em História). Universidade do Estado de Santa Catarina, Centro de Ciências Humanas e da educação, Florianópolis, 2009.

ANDRADE FILHO, Odilon de; BARROS FILHO, Sebastião; HIRTH, Maria Bernadette Pereira. Creches (Organização e Funcionamento). Rio de Janeiro: Ministério da Saúde/Departamento Nacional da Criança, 1956. (Coleção $\mathrm{DNCr} \mathrm{N}^{\circ}$ 151). Disponível em: <https://www.fcc.org.br/pesquisa/educacaolnfancia/Educacaolnfancia.abrirTopico.mtw?i dTopico=6>. Acesso em 10/02/2016.

ARCHIVOS DE ASSISTENCIA A INFANCIA. Nov. 1902; set. 1907; jan. 1913; dez. 1925; jan. 1929; dez. 1946. Rio de Janeiro. Disponível em: <http://www2.dbd.pucrio.br/pergamum/docdigital/MoncorvoFilho/Rolo5/10_Archivos_de_Assistencia_a_Infanci a_Empresa_graphica.pdf $>$. Acesso em: 12/03/214.

ARCHIVOS DE ASSISTÊNCIA À INFÂNCIA: órgão oficial do Instituto de Proteção à Assistência à Infância do Rio de Janeiro. Disponível em: <http://www2.dbd.pucrio.br/pergamum/docdigital/MoncorvoFilho/Rolo5/10_Archivos_de_Assistencia_a_Infanci a_Empresa_graphica.pdf $>$. Acesso em: 12/03/214.

ARNS, Irmã Maria Helena. Histórico das Irmãs Escolares de Nossa Senhora. Colégio

Sagrada Família Forquilhinha - SC. Forquilhinha: Ellus Editora e Gráfica Ltda., 2000. Assistência Social da Empresa Industrial Garcia - EIG. Disponível em: <http://adalbertoday.blogspot.com.br/>. Acesso em: 12/03/ 2012.

BAPTISTA, Olavo. Da protecção á primeira infancia. These. Rio de Janeiro: Besnard Frères, 1901.

BARRETO FILHO, Oscar. Aspectos legais do problema das “creches". São Paulo: Serviço Social, julho-setembro, 1950. Disponível em: 
<https://www.fcc.org.br/pesquisa/educacaolnfancia/Educacaolnfancia.abrirTopico.mtw?i dTopico=6>. Acesso em 10/02/2016.

BASTOS, Maria Helena Câmara. Jardim de Crianças: o pioneirismo do Dr. Menezes Vieira (1875-1887). In: MONARCHA, Carlos (Org.). Educação da infância brasileira (1875-1983). São Paulo: Autores Associados, 2001, p. 31-64.

BATISTA, Rosa. A emergência da docência na educação infantil no Estado de Santa Catarina: 1908-1949, 2013. 198 f. Tese (Doutorado em Educação) - Universidade Federal de Santa Catarina, Florianópolis, 2013.

BIEHL, Zenandria Branco. A criança pobre como justificativa para a construção do Jardim de Infância "Casa da Criança", Criciúma 1945 - 1950. 2006. 47 f. Trabalho de Conclusão de Curso (História) - Universidade do Extremo Sul Catarinense, Criciúma, 2006.

BOLETIM DO CÍRCULO OPERÁRIO DE JOINVILLE. Jornal mensal da entidade, 1938. Arquivo do Círculo Operário de Joinville.

BRASIL. Ministério da Educação e Saúde. Departamento Nacional da Criança. Inquéritos sôbre as instituições de proteção à maternidade e à infância. Rio de Janeiro:

Departamento de Imprensa Nacional, 1952. (Coleção D. N. Cr.) Disponível em:

<https://www.fcc.org.br/pesquisa/educacaolnfancia/Educacaolnfancia.abrirTopico.mtw?i dTopico=6>. Acesso em 10/03/2013.

BRASIL. Ministério da Saúde. Departamento Nacional da Criança. Clube de mães da Campanha Educativa. 1960. (Coleção D. N. Cr. Rio de Janeiro). Disponível em: <https://www.fcc.org.br/pesquisa/educacaolnfancia/Educacaolnfancia.abrirTopico.mtw?i dTopico=6>. Acesso em 10/02/2016.

CAMPOS, Cynthia Machado. Santa Catarina, 1930: da degenerescência à regeneração. Florianópolis: Ed. da UFSC, 2008.

CÍRCULO OPERÁRIO DE JOINVILLE. Atas - livro 1, 1935. Arquivo do Círculo Operário de Joinville.

CIVILETTI, Maria Vittoria Pardal. A creche e o nascimento da nova maternidade. 1988. 188 f. Dissertação (Mestrado em Psicologia) Fundação Getúlio Vargas. Rio de Janeiro, 1988.

COSTA, Marli de Oliveira. Arte de viver: recriando e reinventando espaços, memórias das famílias da vila operária mineira Próspera - Criciúma (1945/1961). 1999, 206 f. Dissertação (Mestrado em História) - Universidade Federal de Santa Catarina, Curso de PósGraduação em História, Florianópolis, 1999.

CRÔNICA do Jardim de Infância Cristo-Rei de Capivari (1960-1970). Instituto Coração de Jesus. Capivari (SC). Acervo Grupo de Pesquisa História e Memória da Educação GRUPHEME, UNESC. 
DAY, Adalberto. Blogspot. 2011. Disponível em: <http://adalbertoday.blogspot.com.br/>. Acesso em: 15 jun. 2011.

DÓRIA, Ulysses. O problema dos menores (estudos e anotações). São Paulo: Imprensa Oficial do Estado, 1951. Disponível em:

<http://www.fcc.org.br/pesquisa/educacaolnfancia/Educacaolnfancia.abrirTopico.mtw?id Topico=6 > . Acesso em: 10/03/ 2014 .

Dr. MONCORVO FILHO. Breves considerações sobre um programa de Protecção á Infancia (apresentado á Conferência Feminista de 1922 no Rio de Janeiro). Trabalho do Departamento da Creança no Brasil. Rio de Janeiro: Typ. Besnard Frères, 1923. Disponível em: <http://www2.dbd.puc-

rio.br/pergamum/docdigital/MoncorvoFilho/Rolo15/58_Breves_consideracoes_sobre_um _programa_de_protecao_a_infa.pdf >. Acesso em: 18/03/2013.

Estatuto do Círculo São José de Cresciuma, (mímeo) 1935. Arquivo Colégio São Bento Criciúma.

ESTATUTOS do Departamento da Creança no Brasil [recurso eletrônico]: fundado pelo Dr. Moncorvo Filho em $1^{\circ}$ de março de 1919. Disponível em: <http://www2.dbd.puc-

rio.br/pergamum/docdigital/MoncorvoFilho/Rolog/19_Estatutos_do_departamento_da_c reanca_no_Brasil.pdf>. Acesso em: 19/02/2013.

FARIAS, Marcilene Nascimento de. Liga de Senhoras Luteranas do Brasil (LSLB): relações de gênero e poder no protestantismo brasileiro. 2016. 249f. Tese (Doutorado em História) - Universidade Federal da Grande Dourados, Dourados, 2016.

FIGUEIREDO, Gastão de. Como prospera o bebê Rio de Janeiro: F. Briguiet, 1938. Disponível em:

<https://www.fcc.org.br/pesquisa/educacaolnfancia/Educacaolnfancia.abrirTopico.mtw?i dTopico=6>. Acesso em: 10/03/2013.

FIGUEIREDO, Gastão de. Creche. 2. ed. Rio de Janeiro: Ministério da Educação e Saúde. Brasilia: Departamento Nacional da Criança - Imprensa Nacional, 1946. (Coleção D. N. Cr. $n^{\circ}$ 95).

FIGUEIREDO, Gastão de. Creche. 2. ed. Rio de Janeiro: Ministério da Educação e Saúde/Departamento Nacional da Criança - Imprensa Nacional, 1946. (Coleção D. N. Cr. N ${ }^{\circ}$ 95). Disponível em:

<https://www.fcc.org.br/pesquisa/educacaolnfancia/Educacaolnfancia.abrirTopico.mtw?i dTopico $=6>$. Acesso em: 10/02/2013.

FIGUEIREDO, Gastão de. Creche. Rio de Janeiro: Imprensa Oficial, 1946. Disponível em: <https://www.fcc.org.br/pesquisa/educacaolnfancia/Educacaolnfancia.abrirTopico.mtw?i dTopico $=6>$. Acesso em: 10/03/2013. 
FREITAS, Marcos Cezar de. (Org.). História social da infância no Brasil. $2^{\mathrm{a}}$. ed. São Paulo: Editora Cortez, 1999.

FRIGOTO, Gaudêncio. Os circuitos da história e o balanço da educação no Brasil na primeira década do século XXI. Revista Brasileira de Educação On-line, Rio de Janeiro, v.16 n.46 jan./abr. 2011. Disponível em:

<http://www.scielo.br/pdf/rbedu/v16n46/v16n46a13>. Acesso em: 10/06/2017.

FUNDAÇÃO CASA DR. BLUMENAU. Centenário de Blumenau 1850 - 2 de setembro - 1950. Blumenau: FCDB, 1950. Disponível: Arquivo Histórico José Ferreira da Silva - Blumenau.

Histórico da OASE - “Grupo Esperança” e Raízes da Paróquia Evangélica Luterana “Bom Pastor" - Garcia. Disponível em: <http://adalbertoday.blogspot.com.br/>. Acesso em: 12/03/2012.

Histórico do Colégio São Bento. Texto Mímeo. Criciúma, s/d. Disponível: Arquivo Colégio São Bento - Criciúma.

Histórico sobre o Jardim de Infância da Rua Jaguaruna, 1963. Arquivo da Paróquia da Paz - Joinville.

HOFF, Sandino; LONGHI, Armindo José; CARDOSO, Maria Angélica. O manual didático e os quadros murais na relação educativa do Curso Normal Sagrado Coração de Jesus: 19361971. Revista HISTEDBR On-line. Campinas-SP, número especial, maio 2010, p. 128-144. Disponível em:

<https://periodicos.sbu.unicamp.br/ojs/index.php/histedbr/article/view/8639785>. Acesso em: $10 / 06 / 2017$.

IMBERT, Jean Baptiste Alban. Guia medica das mães de familia, ou a infancia considerada na sua hygiene, suas molestias e tratamentos. Rio de Janeiro: Typographia Franceza, 1843.

INDÚSTRIA TÊXTIL COMPANHIA HERING. Fundação Hermann Hering. Regulamento. 1947. Arquivo histórico da Cia. Hering - Blumenau.

INDÚSTRIA TÊXTIL COMPANHIA HERING. Relatório da Diretoria e Parecer do Conselho Fiscal. Balanço Geral. Demonstração da Conta de Lucros e Perdas. Anexos e Outros Demonstrativos. Exercício Social 1944/45. Arquivo histórico da Cia. Hering - Blumenau.

ISOTTON, Andréa Patrícia Probst. A influência do luteranismo e do catolicismo nos primeiros jardins de infância em Rio do Sul. Rio do Sul: UNIDAVI, 2004.

JORNAL A GAZETA, Florianópolis, (16, 11, 20 jan.1940; 16, 20, 21, 26, 29, 30, 31 mar. 1940; 2, 3, 5, 7 abr. 1940; 12 jul.1940; 10 out. 1940). Acesso: BPESC, 2012.

JORNAL A NOTíCIA, Joinville (11 jul.11; out.1942; 5 jan. 10; out. 1943). Acesso: BPESC ,2012. 
JORNAL CORREIO DA MANHÃ, 28/12/1937. Acesso: Arquivo Histórico Municipal Pedro Milanez, Criciúma, 2011.

KILIPPER, Karina. As pequenas missionárias da caridade e suas práticas pedagógicas no Jardim de Infância Nossa Senhora Aparecida junto aos filhos dos operários da CSN (Siderópolis). 2008. 72 f. Trabalho de Conclusão de Curso (Pedagogia) - Universidade do Estado de Santa Catarina, 2008.

KISHIMOTO, Tizuko Morchida. A Pré-escola em São Paulo: das origens a 1940. São Paulo: USP, 1986. 344 f. Tese (Doutorado em Educação) - Universidade de São Paulo, 1986.

KISHIMOTO, Tizuko Morchida. Os jardins de Infância e as escolas maternais de São Paulo no início da República. Cadernos de Pesquisa, São Paulo, n. 64, fev. 1988, p. 57-60.

KOLB, Alberto. Histórico do Círculo Operário através da imprensa. Fatos e não palavras. Amparando os proletários catarinenses. Livros nº 1 [s/d]; 2 [s/d]; 3 [1941/42]; 4 [1942/46]. Acesso: Arquivo do Círculo Operário de Joinville (COJ), 2013.

KOLB, Padre Alberto. Reminiscências para a história do Círculo Operário. Livros nº 2, 4. Acesso: Círculo Operário de Joinville (COJ), 2013.

KRAMER, Sônia. A política do pré-escolar no Brasil: a arte do disfarce. Rio de Janeiro: Achiamé, 1982.

KUHLMANN JUNIOR, Moysés. A circulação das ideias sobre a educação das crianças: Brasil, início do século XX. In: FREITAS, Marcos Cezar de; KUHLMANN JUNIOR, Moysés (Orgs.). Os intelectuais na história da infância. São Paulo: Cortez, 2002, p. 459-503.

KUHLMANN JUNIOR, Moysés. Infância e educação infantil: uma abordagem histórica. Porto Alegre: Mediação, 1998.

KUHLMANN JUNIOR, Moysés. O Jardim-de-Infância e a educação das crianças pobres: final do século XIX, início do século XX. In: MONARCHA, Carlos. (Org.). Educação da infância brasileira: 1875-1983. Campinas: Autores Associados, 2001, p. 3-30.

Livro de atas $\mathbf{n}^{\circ} \mathbf{1}$ da Associação Católica Círculo São José, 1952. Acesso: Arquivo Colégio São Bento - Criciúma, 2012.

Livro de Crônicas do Paraíso da Criança (10/05/1948 - 30/10/1958). Acesso: Acervo pessoal de Ida Bez Batti - Urussanga, 2012.

MANCINI, Guiomar Urbina Telles. As creches como auxiliares da Família. São Paulo:

Serviço Social, set. 1944. Disponível em:

<https://www.fcc.org.br/pesquisa/educacaolnfancia/Educacaolnfancia.abrirTopico.mtw?i dTopico=6>. Acesso: 10/03/2013.

MARQUES, Agenor Neves. História de Urussanga. Urussanga: Prefeitura Municipal, 1960. 
MIRANDA, Carmen Silva Meyer. Creche Conde Modesto de Leal: o legado social de padre Kolb. Joinville: Letra d’Água, 2006.

MONCORVO FILHO, Arthur. Archivos de assistência á infância. Rio de Janeiro. V. III, N. 1-3, jan. fev. mar., 1904. Disponível em: <http://www2.dbd.puc-

rio.br/pergamum/docdigital/MoncorvoFilho/Rolo5/06_Archivos_de_Assistencia_a_Infanci a_Emp_graphica.pdf>. Acesso em: 12/02/2013.

MONCORVO FILHO. A infancia da primeira edade no Rio de Janeiro. In: CONGRESSO LATINO AMERICANO, 4., 1909, Nota [recurso eletrônico] Rio de Janeiro, 1909. Disponível em: <http://www2.dbd.puc-

rio.br/pergamum/docdigital/MoncorvoFilho/Rolo3/1_A_infancia_da_primeira_edade.pdf>. Acesso em: 19/02/2013.

MONCORVO FILHO. Algumas considerações sobre o problema da infancia no Brasil. Publicação, Departamento da Creança no Brasil, $n^{\circ} 79$, s.d. Disponível em:

$<$ http://www2.dbd.puc-

rio.br/pergamum/docdigital/MoncorvoFilho/Rolo7/14_Algumas_consideracoes_sobre_o_ problema_da_infancia.pdf $>$. Acesso em: 12/02/2013.

MONCORVO FILHO. Instituto de Protecção e Assistência á Infancia do Rio de Janeiro.

Archivos de Assistência á Infancia. Distribuição Gratuita. Rio de Janeiro, 1917. Disponível em: <http://www2.dbd.puc-

rio.br/pergamum/docdigital/MoncorvoFilho/Rolo17/140_IPAI_A_tribina_medica.pdf $>$. Acesso em: 20/3/2013.

OLIVEIRA, Olinto de. A casa da criança. 3. ed. Rio de Janeiro: Ministério da Educação e Saúde/Departamento Nacional da Criança - Imprensa Nacional, 1946. (Coleção D. N. Cr. N ${ }^{\text {o. }}$ 72). Disponível em:

<https://www.fcc.org.br/pesquisa/educacaolnfancia/Educacaolnfancia.abrirTopico.mtw?i dTopico $=6>$. Acesso em: 10/03/2013.

PERROT, M. As mulheres, o poder a história. In: PERROT, M. Os excluídos da história: operários, mulheres e prisioneiros. Tradução: Denise Bottmann. Rio de Janeiro: Paz e Terra, 1988. p. 167-184.

PIERI, Marlise de Medeiros Nunes. Gênese do atendimento às crianças em instituições infantis no município de Tubarão/SC (1950-1990). Tubarão: UNISUL, 2011.

RABELO, Giani. Entre o hábito e o carvão: pedagogia missionária no sul de Santa Catarina na segunda metade do século XX. 2007. 412 f. Tese (Doutorado em Educação) Universidade Federal do Rio Grande do SUL, 2007.

REVISTA DO JARDIM DE INFÂNCIA. V. I e II. São Paulo, Typographia de Espindola, Siqueira e Comp., Publicação Official do Governo do Estado de São Paulo, 1896 - 1897 (impresso).

ROCHA, Eloisa Acires Candal. A invenção da professora de educação infantil. Relatório de 
pesquisa de estágio pós-doutoral. PPGE-PUC-RJ, 2012. (não publicado)

SANTA CATARINA (Estado). Decreto-lei n. 306, de 2 de março de 1939 - reorganiza o Instituto de Educação. Coleção de Decretos-Leis de 1939, Florianópolis, 1939. Acesso: APESC, 2011.

SANTA CATARINA (Estado). Regulamento Geral da Instrução Pública do Estado de Santa Catarina de 1908: Título II, Capítulo I, Artigo 9², p. 7, 1908. Acesso: APESC, 2011.

SANTA CATARINA (Estado). Regulamento Geral da Instrução Pública do Estado de Santa Catarina de 1908, Título VIII, Capítulo Único, Artigo 204, p. 34, 1908.

SANTA CATARINA (Estado). Relatório apresentado ao Dr. Otávio da Rocha Miranda, Presidente da comissão central da Legião Brasileira de Assistência, pelo presidente da comissão estadual de Santa Catarina, Dr. Ylmar Corrêa. Florianópolis, Imprensa Oficial do Estado 1948. Acesso: ABPESC, 2011.

SANTA CATARINA (Estado). Relatório do Interventor Federal Nereu Ramos apresentado ao Presidente da República. Florianópolis: Imprensa Oficial, 1939 e 1943. Acesso: APESC, 2011.

SANTA CATARINA (Estado) Relatório apresentado à Exma. Sra. D. Darci Samanho Vargas, DD. Presidente da Comissão Central da Legião Brasileira de Assistência, no Rio de janeiro, pela Senhora D. Beatriz Pederneira Ramos, presidente da comissão estadual da LBA em Santa Catarina. Florianópolis, Imprensa Oficial do Estado, 1943 e 1945. Acesso: ABPESC, 2011.

SANTA CATARINA. SECRETARIA DO INTERIOR E JUSTIÇA, EDUCAÇÃO E SAÚDE.

Departamento de Saúde Pública. Atestado. 1952. Acesso: Arquivo histórico da Cia. Hering - Blumenau, 2012.

SANTA CATHARINA (Estado). Decreto n. 348, de 7 de dezembro de 1907: Regulamento Geral da Instrução Pública. Florianópolis, Typ. Gutenberg, 1908. Acesso: APESC, 2012.

SANTA CATHARINA (Estado). Lei n. 967, de 22 de Agosto de 1913. Acesso: APESC, 2012.

SAVIANI, Dermeval. Breves considerações sobre fontes para a história da educação.

Revista HISTEDBR On-line, Campinas, n. especial, p. 28-35, ago. 2006. Disponível em: <http://www.histedbr.fe.unicamp.br/revista/edicoes/22e/art5_22e.pdf >. Acesso em: 15/05/2017.

SAVIANI, Dermeval. Entrevista com Dermeval Saviani. Acervo, Rio de Janeiro, v. 18, p. 514, jan./dez., 2005. Disponível em:

<http://revista.arquivonacional.gov.br/index.php/revistaacervo/article/view/182>. Acesso em: 20/04/2017. 
SERAFIM, Marjourie Mariano. Jardim de Infância na Vila Operária no Bairro Próspera na década de 1960. 2009. 61 f. Trabalho de Conclusão de Curso (Pedagogia) - Universidade do Extremo Oeste Catarinense, Criciúma, 2009.

SEYFERTH, Giralda. A conflituosa história da formação da etnicidade teuto brasileira. In: FIORI, Neide A. (Org.) Etnia e educação: a "escola alemã” do Brasil e estudos congêneres. Florianópolis: Ed. da UFSC; Tubarão Unisul, 2003. p. 21-61.

SOCIEDADE DE ASSISTÊNCIA AOS LÁZAROS E DEFESA CONTRA A LEPRA EM SANTA CATARINA. Relatórios (1941 e 1944). Acesso: BPESC, 2012.

SOUZA, Gizele de. Instrução, o talher para o banquete da civilização: cultura escolar dos jardins-de-infância e grupos escolares no Paraná, 1900-1929. 2004. 299 f. Tese (Doutorado) - Programa de Estudos Pós-Graduados em Educação: História, Política, Sociedade, Pontifícia Universidade Católica/SP, São Paulo, 2004.

SÚMULA DOS ESTATUTOS DOS CíRCULOS OPERÁRIOS. Princípios Básicos. Acesso: Círculo Operário de Joinville (COJ), 2012.

THOMPSON, E. P. A miséria da teoria ou um planetário de erros (uma crítica ao pensamento de Althusser). Rio de janeiro: Zahar, 1981, p. 47-62.

URUSSANGA (SC). Paraíso da criança. República Federativa dos Estados Unidos do Brasil - Registro Civil - Estado de Santa Catarina. - Urussanga. Certidão, 25 de janeiro de 1958 (5 folhas), 2011.

VASCONCELOS, J. Freire de; SILVEIRA, Sampaio. Problemas médico-sociais da infância, o comércio das criadeiras. Rio de Janeiro: Livraria Odeon. 1938. Disponível em: <https://www.fcc.org.br/pesquisa/educacaolnfancia/Educacaolnfancia.abrirTopico.mtw?i dTopico=6>. Acesso em: 10/03/2013.

VIEIRA, Lívia Maria Fraga. Creches no Brasil: de mal necessário a lugar de compensar carências rumo à construção de um projeto educativo. 1986. Dissertação (Mestrado em Educação) - Universidade Federal de Minas Gerais, Faculdade de Educação, Belo Horizonte, 1986.

Universidade do Estado de Santa Catarina - UDESC Programa de Pós-Graduação em Educação - PPGE Revista Linhas Volume 19 - Número 41 - Ano 2018 revistalinhas@gmail.com 